ORIENTAL JOURNAL OF CHEMISTRY

An International Open Free Access, Peer Reviewed Research Journal

www.orientjchem.org
ISSN: 0970-020 X

CODEN: OJCHEG

2015, Vol. 31, No. (1):

Pg. 357-361

\title{
Bioremediation of Heavy Metals by Employing Resistant Microbial isolates from Agricultural Soil Irrigated with Industrial Waste Water
}

\author{
VIJAY KUMAR ${ }^{1}$, SIMRANJEET SINGH ${ }^{2}$, POOJA BHADRECHA ${ }^{2}$, PARVINDER KAUR ${ }^{2}$, \\ DEEPIKA BHATIA ${ }^{2}$, SOURAV SINGLA ${ }^{2}$, SHIVIKA DATTA ${ }^{3}$, VIKAS CHANDEL ${ }^{2}$, \\ MUDDASIR AHMAD BHAT ${ }^{2}$, NIVEDETA KASHYAP ${ }^{2}$, ARJUN KALIA ${ }^{2}$ and JOGINDER SINGH ${ }^{2 *}$
}

1Department of Chemistry, Lovely Professional University, Phagwara, Punjab, India.

${ }^{2}$ Department of Biotechnology, Lovely Professional University, Phagwara, Punjab, India.

${ }^{3}$ Department of Zoology, Lovely Professional University, Phagwara, Punjab, India.

${ }^{*}$ Corresponding E-mail: simnav14@gmail.com

http://dx.doi.org/10.13005/ojc/310142

(Received: December 08, 2014; Accepted: January 12, 2015)

\begin{abstract}
A total of 14 microbial isolates werecharacterized and out of 14 , IS 1 and IS14 were observed to be most effective because of their high relative growth and resistance against heavy metals. Further, these two isolates were assessed for their ability to remove Zinc and Lead from medium amended with heavy metals. IS1, Bacillus thuringiensis strain "Simi" (Accession number KF 916618.1) was found to be more effective as compared to IS14, Bacillus subtilis strainPSB (Accession number KF 279045.1) for the remediation of heavy metals. IS1 showed mean of 54\% biodegradation efficacy in the first three days and from day 4 onwards the mean percentage of biodegradation efficacy decreased to around $31 \%$. The results of the present study showed that the metal resistant bacteria can be used for heavy metal bioaccumulation.
\end{abstract}

Key words: ICP-AES, Phylogenetic tree, waste water, Hydrocarbons.

\section{INTRODUCTION}

The presence of heavy metals and pesticides in the environment has been a subject of great concern due to their toxicity, nonbiodegradable nature and the long biological halflives for their elimination from biological tissues ${ }^{1-5}$.
Pollutants deteriorates the quality of soil and crops produced. Excessive metal concentrations and pesticides in contaminated soils can result in decreased soil microbial activity and soil fertility, and yield losses ${ }^{2-3}$. Agricultural irrigation with wastewater is common in arid areas but has possible public health and environmental side 
effects, as effluent may contain pathogens, high level of salts, detergents and toxic metals ${ }^{2-5}$. There is a need for monitoring of toxic effects of wastewaters and such irrigation practices should be carried out only after treatment of wastewater. Numerous methods have been proposed to remove heavy metals from sewage sludge, including chlorination, use of chelating agents and acid treatments at high temperatures ${ }^{6-7}$. However, those methods are generally ineffective in practical applications due to high cost, operational difficulties and low metal leaching efficiency. An alternative way to replace chemical methods in removing heavy metals is bioremediation through microbial isolates.

The bioremediation techniques are effective and efficient for remediation of pollutants so as the bioremediation technology from laboratory to field to clean up the environment can be taken up $^{8}$. For bioremediation to be effective, microorganisms must enzymatic ally attack the pollutants and convert them to harmless products ${ }^{9}$. As bioremediation can be effective only where environmental conditions permit microbial growth and activity, its application often involves the manipulation of environmental parameters to allow microbial growth and degradation to proceed at a faster rate. These factors include the existence of a microbial population capable of degrading the pollutants; the availability of contaminants to the microbial population; the environment factors ${ }^{10}$. Therefore, this study was designed with the objective to isolate and characterize metal (Zinc and lead) resistant bacteria from heavy metal contaminated soil to determine their feasibility on the removal of metals through bio-accumulation.

\section{Methodology \\ Collection and Physicochemical Analysis of soil samples}

Soil samples were collected from the top $15 \mathrm{~cm}$ from industrial effluents of the Ludhiana (Punjab) region $\left(30.91^{\circ} \mathrm{N} 75.85^{\circ} \mathrm{E}\right)$. These samples were collected in sterile zip lock bags with the help of sterilized spatula, properly sealed and labeled, and sent to the laboratory within 24 hours. Heavy metals in soil were analyzed by inductively coupled plasma-atomic emission spectrometry at P.A.U., Ludhiana (ICP-AES).
Isolation\&Identification of the microorganism Isolation was done by the method as described by Jyothi ${ }^{11}$.Isolated microbes were identified through morphological, biochemical\& molecular characterization ${ }^{12}$.

\section{Determination of comparative growth and growth pattern}

Extent of heavy metal resistance of selected microbial isolates was evaluated in bacillus cereus broth (bacteria) containing 25, 100, 250 and 300 ppm of Lead nitrate $\mathrm{Pb}\left(\mathrm{NO}_{3}\right)_{2}$, Copper sulphate $\mathrm{CuSO}_{4}$, Zinc nitrate $\mathrm{Zn}\left(\mathrm{NO}_{3}\right)_{2}$ and Ferrous sulphate $\mathrm{FeSO}_{4}$ and growth is determined by measuring Optical density (O.D.)at $540 \mathrm{~nm}$ with un-inoculated broth as control. To check the growth pattern of the isolates, cultures were inoculated into broth, treated with 0 (control), 25, 100, 250 and $300 \mathrm{ppm}$ of $\mathrm{Pb}\left(\mathrm{NO}_{3}\right)_{2}, \mathrm{CuSO}_{4}, \mathrm{Zn}\left(\mathrm{NO}_{3}\right)_{2}$ and $\mathrm{FeSO}_{4}$, and incubated at $37^{\circ} \mathrm{C}^{13}$

\section{Molecular analysis}

Isolates showing high resistant against heavy metals were sent for 16S rRNA analysis to Ahmedabad, Gujarat for molecular analysis ${ }^{14-15}$.

\section{Minimum Inhibitory Concentration (MIC)} determination of the isolated strains

Bacillus cereus agar plates and yeast peptone dextrose agar plates were inoculated with $100 \mathrm{\mu l}$ aliquots of $24 \mathrm{hr}$ culture with all isolates with different concentrations of $\mathrm{Pb}\left(\mathrm{NO}_{3}\right)_{2}, \mathrm{CuSO}_{4}, \mathrm{Zn}$ $\left(\mathrm{NO}_{3}\right)_{2}$ and $\mathrm{FeSO}_{4}(250,500,750,1000,1250$ and $1500 \mathrm{mg} / \mathrm{l}$ ).Diameter of inhibition zones were measured (in $\mathrm{mm}$ ) in order to determine the $\mathrm{MIC}^{16}$.

\section{Efficacy of isolated strains on bioaccumulation of heavy metals}

$80 \mu \mathrm{l}$ of the bacterial inoculum was inoculated into test tubes containing $8.0 \mathrm{~mL}$ of broth supplemented with 100ppm of zinc \& lead. The control treatment was prepared by mixing $9.0 \mathrm{ml}$ of broth with $1.0 \mathrm{ml}$ of bacterial suspension. All the tubes were sealed with parafilm and kept at $27 \pm 2^{\circ} \mathrm{C}$ for 7 days. To determine degradation efficacy, the heavy metal was first extracted with sequential extraction method ${ }^{17}$ diluted $10^{-4}$ times and the absorbance was recorded at $225 \mathrm{~nm}^{18}$. The biodegradation efficacy (BE) was calculated using the following formula $\mathrm{BE}$ $(\%)=100-(\text { As/Aac } \times 100)^{19,20}$. 


\section{RESULTS AND DISCUSSION}

Soil analysis reportand enumeration of bacteria

Soil analysis report shows the presence of various toxic heavy metals and sample contains Arsenic $(0.756 \mathrm{mg} / \mathrm{kg})$, Calcium $(327.9 \mathrm{mg} / \mathrm{kg})$, Cadmium $(0.09 \mathrm{mg} / \mathrm{kg})$, Cobalt $(0.02 \mathrm{mg} / \mathrm{kg})$, Chromium $(0.053 \mathrm{mg} / \mathrm{kg})$, Copper $(9.4 \mathrm{mg} / \mathrm{kg})$, Iron $(53.71 \mathrm{mg} / \mathrm{kg})$, Potassium (118.6mg/kg), Magnesium $(202.7 \mathrm{mg} / \mathrm{kg})$, Manganese $(4.539 \mathrm{mg} /$ $\mathrm{kg})$, Sodium $(59.91 \mathrm{mg} / \mathrm{kg})$, Nickel $(0.723 \mathrm{mg} / \mathrm{kg})$, Phosphorous $(65.02 \mathrm{mg} / \mathrm{kg})$, Lead $(8.387 \mathrm{mg} / \mathrm{kg})$, and Zinc $(10.8 \mathrm{mg} / \mathrm{kg})$. A total of fourteen different isolates (IS1,IS2, IS3, IS4, IS5, IS6, IS7, IS8, IS9, IS10, IS11, IS12, IS13, and IS14) were isolated andare biochemically and molecularly characterized and best two having high resistant

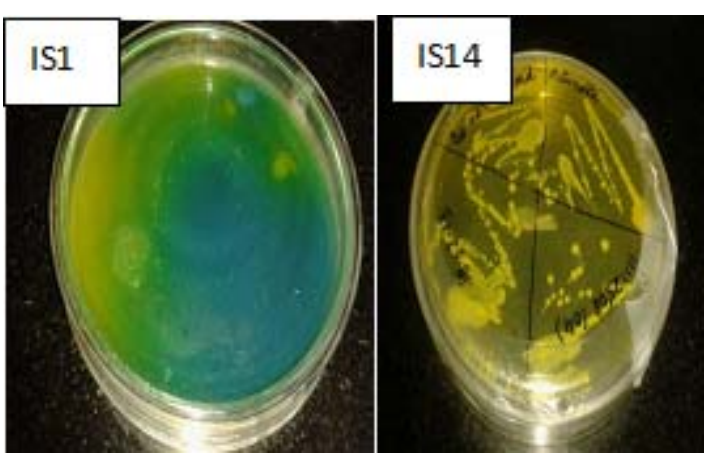

Fig. 1: Isolation of the microorganisms

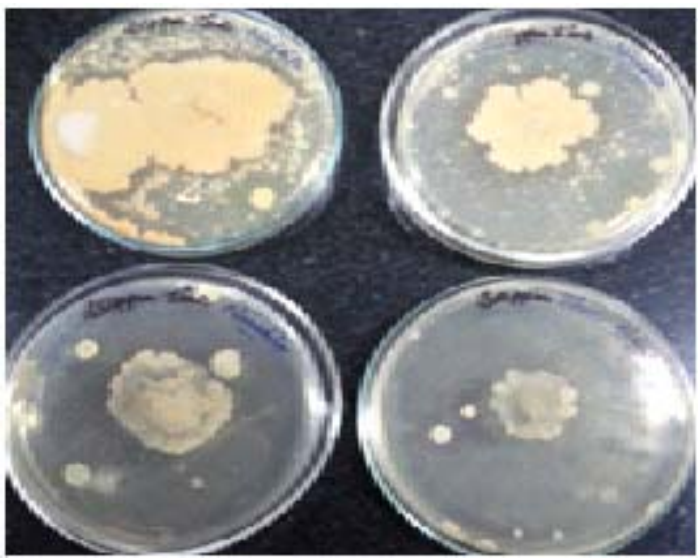

Lead sulphite against metals were further selected for bioaccumulation \& heavy metal testi.e. IS1 and IS 14. The biochemical and isolated results were shown in fig. 1 and table 1.

Table 1: Biochemical tests

\begin{tabular}{lcc} 
Test & IS1 & IS14 \\
\hline Indole test & - & - \\
Methyl red & + & + \\
VogesProskauer & - & + \\
Citrate & + & - \\
Catalase & + & + \\
Coagulase & - & + \\
Motility & + & - \\
Nitrate reduction & + & + \\
\hline
\end{tabular}

Relative growth determination of isolates and their growth pattern

It was observed that the growth of the isolate decreases with the increase in metal concentration. IS1Bacillus thuringiensis strain Simiand IS14 was found to have maximum relative growth against Lead and Zinc solution. The relative growth rate was observed at different concentration of heavy metals. The results are consisted with Ahemad and Malik ${ }^{15}$. Thegrowth pattern of the microbial isolates at different concentration (25, 100, 250\&300 $\mathrm{mgml}^{-1}$ )areshown below:
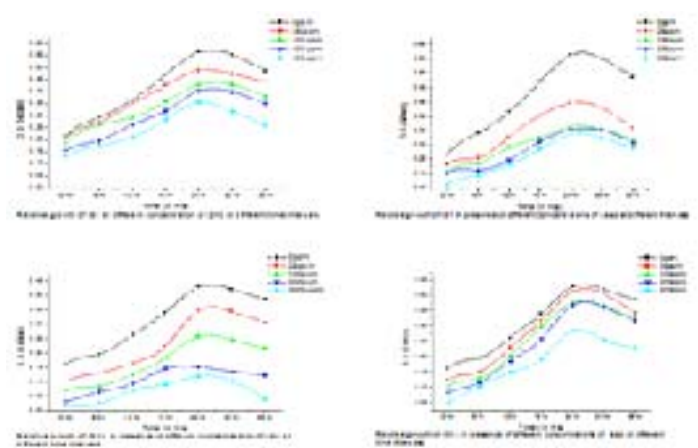

Zinc nitrate

Fig 2. Isolates amended with different concentrations of metals \& Graph showing relative growth of isolates at different concentrations (Control, 25ppm, 100ppm 200ppm, 300ppm of metal solution) of Zinc and Lead 


\section{Heavy metal tolerancetest}

All the isolates were tested for heavy metal tolerance test against $\mathrm{Pb}(\mathrm{NO} 3) 2$, and $\mathrm{Zn}$ (NO3)2. ThelS1 exhibited maximum tolerance for zinc and IS14exhibited maximum tolerance for lead and the results are shown in figure 3 .

\section{Table 2: Minimum inhibitory} concentration $\left(\mu \mathrm{gmL}^{-1}\right)$

\begin{tabular}{lcc}
\hline Metals & IS1 & IS14 \\
\hline Zinc & $960 \pm 10$ & $100 \pm 10$ \\
Copper & $100 \pm 10$ & $500 \pm 10$ \\
Lead & $250 \pm 10$ & $1000 \pm 10$ \\
Iron & $250 \pm 10$ & $500 \pm 10$ \\
\hline
\end{tabular}

\section{6srRNAsequenceanalysis}

The isolates IS1 and IS14 were found similarto Bacillus thuringiensis strainsimi \& Bacillus subtilis under accession number KF916618.1 \& KJ489411.1, when submitted in NCBI. The phylogenetic tree shows relationship of isolated strains with other species.

\section{Determination of Minimum Inhibitory Concentration (MIC) \\ A great dealofvariation among the isolates} against the different heavy metals was observed. The results in Table 8 reveal that MIC of Zinc for Bacillus thuringiensis strain Simi was at $1000 \mu \mathrm{g} /$ $\mathrm{ml}$ where as Bacillus subtilis strain PSB had maximum MIC for lead.

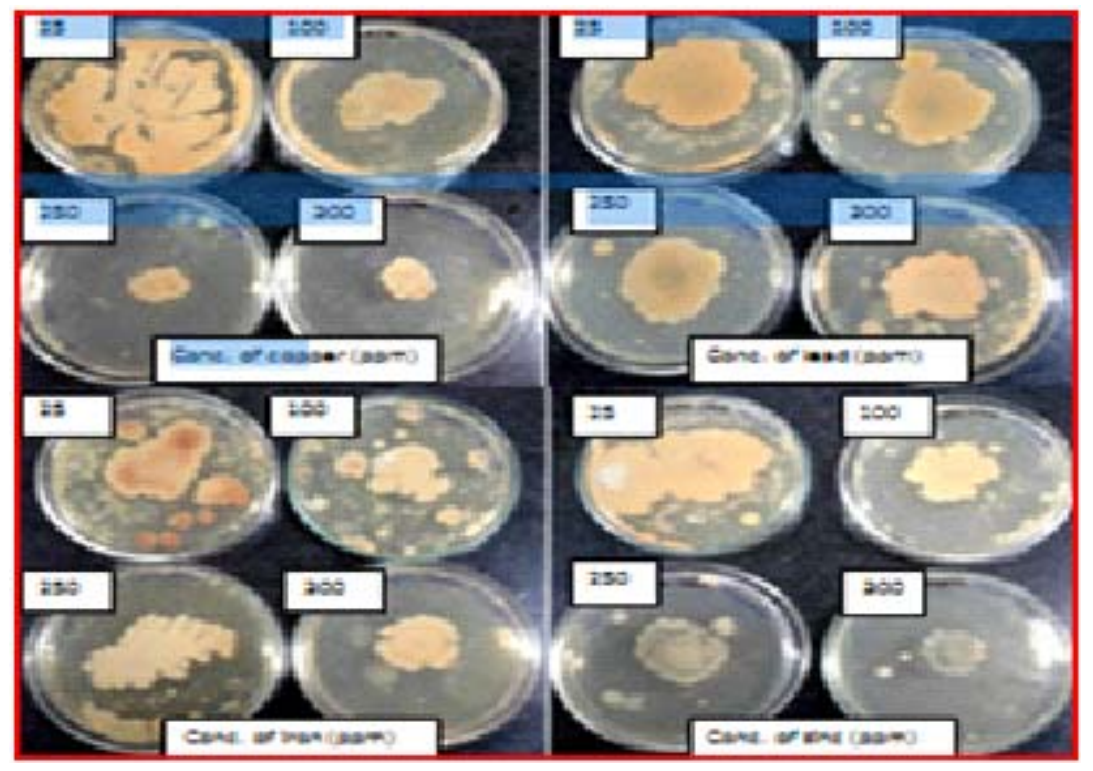

Heavy metal tolerancetest for IS1\& IS14

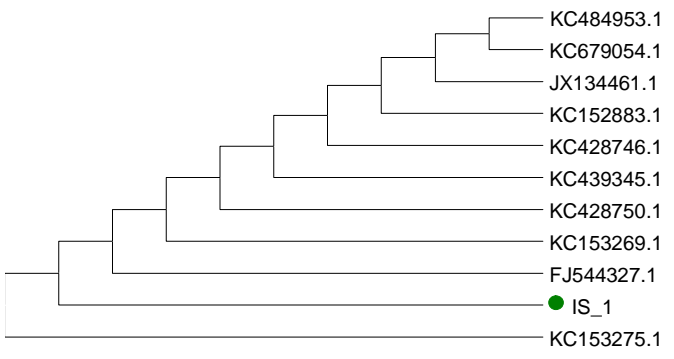

Phylogenetic tree IS1

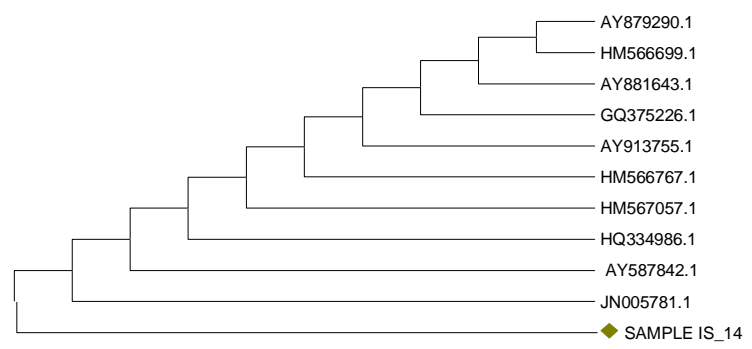

Phylogenetic tree IS 14 


\section{Biodegradation efficacy on heavy metals}

The degradation efficacy of Bacillus thuringiensis strain Simi on zinc showed rapid degradation in the first threedays, with mean of $54 \%$ biodegradation efficacyafter fourth day the degradation efficacy decreased and reached to the

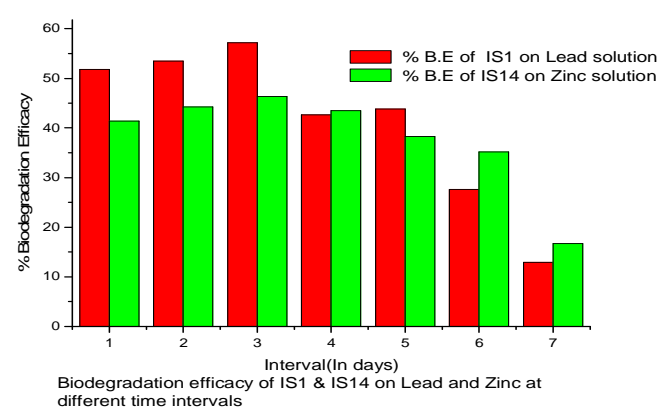

Efficacy of IS1 and IS14 on Biodegradation of lead and Zinc solution point of $31 \%$ and Bacillus subtilis strain PSB showed less degradation activity but the decrease in degradation efficacy started after fifth day. Similar work has already been reported against the hydrocarbon degradation by the isolate $P$. lundensis UTAR FPE2 ${ }^{18 .}$

\section{CONCLUSION}

The removal of heavy metals or breakdown into harmless state has become necessary. Thus bioremediation can be employed for the removal of such contaminants. This study of Zinc and lead accumulation by the isolates from heavy metal contaminated soils revealed a good and positive sign for its further use in bioremediation of zinc and lead in contaminated sites. The current study has illustrated some basic considerations that are important for the use of metal accumulating bacteria for bioremediation under field conditions.

\section{REFERENCES}

1. Kumar, V.; Upadhyay, N.; Wasit, A.B.; Singh, S.; Kaur, P. Curr World Environ.2013, 8(2), 313-318.

2. Kumar, V.; Upadhyay, N.; Singh, S.; Singh, J.; Kaur, P.Curr World Environ.2013,8, 469-473.

3. Kumar, V.; Upadhyay, N.; Kumar, V.; Kaur, S.; Singh, J.; Singh, S.; Datta, S. J. Bio. Env. Sci. 2014,5, 111-120.

4. Prasad, R.; Upadhyay, N.; Kumar, V. Microchem. J.2013, 111, 91-97.

5. Kumar, V.; Upadhyay, N.; Kumar, V.; Sharma, S. J. Bio. Env. Sci. 2014,5, 149-165.

6. Olatunji,B.O.;Deacon,B.J.; Abramowitz, J.S.Cog. Behav Sci.2009,3(2), 172-180.

7. Faryal,R.;Faheem,T.;Abdul,H.Pak. J. Bot.2007,39(1),193-204.

8. Hamby, D.Sci Direct.1996,191(3),203-224.

9. Pandey,B.Fulekar, M.H.Biol Med. 2012,4(1),51-59.

10. Mueller,J.G.Cerniglia, C.E.; Pritchard, P.H.In Bioremed Principles App.1996,3,125-194.
11. Sharma,S. Asian J Pharm Life Sci. 2012 , 2(2), 202-213.

12. Jyothi, N.; Rao,U.V. Iran. J. Microbiol. 2009, 1(3), 23-30.

13. Aneja, K.R.Experiments in Microbiology, Plant Pathology and Biotechnology, Wishwa Prakashan New Delhi(1993).

14. Ahemad,M.;Malik,A.BacteriolJ. 2012,2,1221.

15. Amann, R.I.;Ludwig,W.; Shleifer,K.H. Microbiol. Rev.1995,59,143-169.

16. Pace,N.R.;Stahl, D.A.;Lane,D.J.Olsen GJ Adv. Gen. Microbiol. Ecol.1986,9,1-55.

17. Murthy, S.;Bali, G.;Sarangi,S.K.Int JMicrobiolRes. 2012, 4(3),196-200.

18. Emmerich, W.E.; Lund, L.J.;Page, A.L. J Environ. Qual.1997,11, 178-192.

19. Adeline,T.;Carol,S.Y.;Tan,H.C. Aw,C.Malays J Microbiol. 2009,5(2),104-108.

20. Michaud,L.; Giudice, A.L.; Saitta, M.; Domenico, M.D.;Bruni, V.MarinPollution Bull.2004,45,405-409. 